\title{
The Internal Control Research of Accounting Information System Based on OPM3 Model
}

\author{
ZONG Sheng ${ }^{1, a}$ \\ ${ }^{1}$ Jilin Business and Technology College, Changchun 130507, China \\ azongsheng@163.com
}

Keywords: Accounting Information System; OPM3 Model; Internal Control

\begin{abstract}
The development of the network and the application of information technology makes the enterprise to establish the enterprise information system, when the information system is applied to the finance department, the accounting information system can develop and implement the business integration enterprise financial department and other departments, makes the financial department become the core of the enterprise. In order to ensure that accounting information is reliable, it is necessary to have a set of corresponding system to control, and the system environment has a lot of contact with the outside world, therefore, the internal control of accounting information system should be based on the network environment, this paper is based on the background to study the internal control of accounting information system under the network environment, and OPM3 model in an enterprise as a concrete case to analysis, to further verify the rationality of the model set.
\end{abstract}

\section{Introduction}

The progress of modern science and technology promoted the rapid development of computer technology, network technology support for the computer is widely used to provide a wider platform, with the trend of the technology constantly updated, accounting work, there is a new situation, the accounting information has become the development trend of the accounting work. Accounting information system for the accounting personnel has brought a lot of convenient, but at the same time, convenient behind is not perfect, there are some risks [1-2]. Therefore, in order to ensure that the accounting information system can run normally, needs by continuously grope for perfecting the system of internal control of accounting information system, in order to satisfy the business enterprise development, better avoid risks.

For an enterprise as a whole, the effect of internal control is to standardize enterprise's daily operation, guarantee the stability of enterprise to run effectively, improve the management level of enterprises, therefore, in order to guarantee the normal operation of the financial department, and pay much attention to the internal control of accounting information system will need to. Timely adjust enterprise according to the change of the external environment of internal control system, to ensure that the accounting information is reliable, can provide valuable information for enterprise managers, it also enables managers to make better decisions for enterprise in time [3]. This article first introduces the relevant research on internal control of accounting information system at home and abroad, then starting from the five elements of internal control, through analyzing the characteristics of the internal control of accounting information system, introducing the organizational project management maturity model (OPM3), and finally build a key indicators for the accounting information system internal control, for the enterprise internal control evaluation provides a new train of thought.

\section{Related theory of OPM3}

OPM3 is a detailed annotation according to best practices and the ability of knowledge, the framework of evaluation and improvement process, to help the organization measure its single project management, project management and the implementation of the project portfolio management level, and improve their maturity [4]. OPM3 with the single project, project and 
portfolio management level domain structure, to represent the actual business of mixture, the degree of control and increasing the complexity of the complex, hierarchical domain also became construct the basic dimensions of OPM3 best practices. Each level of the domain business is mixed degree of variation with the organization's strategic measures and operating process of the complexity of the corresponding [5].

As a descriptive framework, OPM3 describes the effective management methods and processes in the field of project management features, it follows the basic principles, namely, each method and the process relies on one or more of the following skills or qualifications, and the skills and qualifications are can be measured and evaluated. The maturity of continuous spectrum represents a linear notice mature approach of gradual process. Through a review of enterprise maturity, can find out enterprise already have best practices, and not have to determine improvement direction and improvement focus, to provide support and guarantee the realization of the organization's strategic goals. Combined in this paper, the research of the internal control of accounting information system under the network environment, the increasing improvement of the level of process, is also the enterprise accounting information system and perfecting internal control process [6]. With the demand of this article, we will be the first dimension is divided into five level gradient, OPM3 model of the relationship between each level is shown in figure 1.

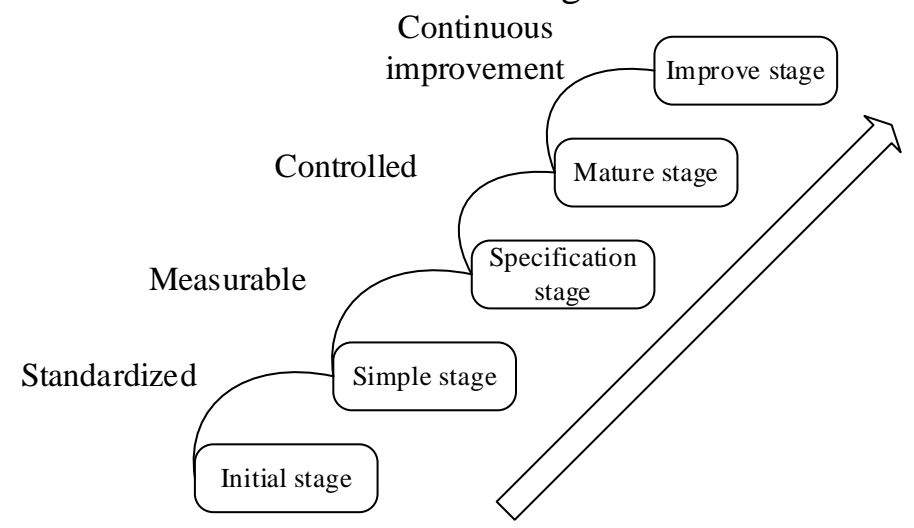

Figure 1.Gradient level of OPM3

\section{Construction of accounting information system internal control OPM3 model}

Accounting information system of internal control system consists of six parts: target, planning, development control, operation control, risk control, evaluation of control in this paper, first of all, the five elements of internal control as the basic control elements of the five basic elements as the starting point, and then determine the control points of the five elements, and then on the basis of various control points, respectively, to determine the control objectives, the specific process as shown in figure 3.

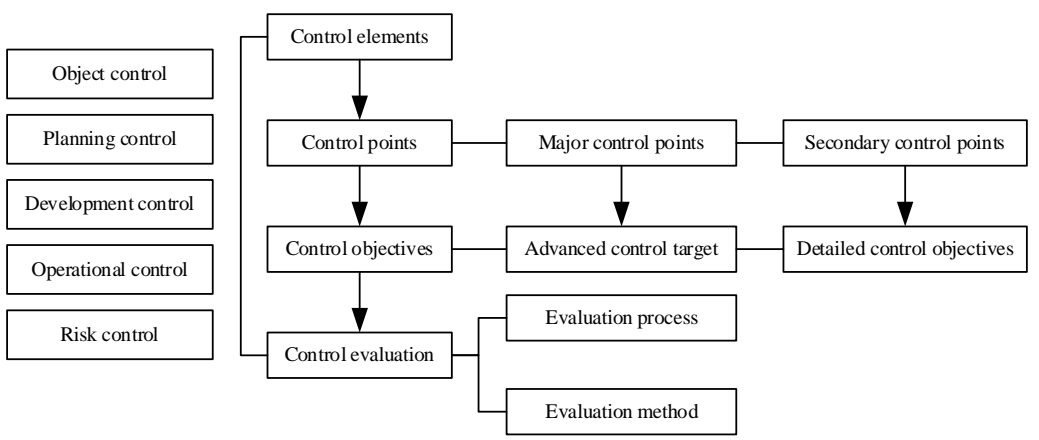

Figure 2. Accounting information system internal control

After setting up various elements of the control points, we can combine OPM3 two-dimensional frame concrete evaluation and analysis of the model. Both enterprise's internal control, and internal control of accounting information system, is composed of five elements, each element is under the influence of many factors, therefore, we will first factors that affect the five elements to analyze the 
specific list, find out the influence factors of concrete, according to the influence degree of these factors, to endow them with different proportion, then according to the degree of the influence of the five elements of internal control, calculate the level of internal control, which can clearly know the internal control system of the enterprise are in what kind of level. Finally according to the result of calculation, layer upon layer analysis, find out the drawbacks and improvement opinions are put forward.

\section{Evaluation research of accounting information system internal control based on OPM3 model}

After OPM3 model of accounting information system is established, and then we determine the accounting information system internal control the five element to the specific control points, and then to evaluate an enterprise for specific. Due to the five elements of internal control of accounting information system of internal control is the influence degree of the whole range, and it is difficult to differentiate clear boundaries, ambiguity exists, so we adopt fuzzy comprehensive evaluation method to evaluate. The following to the evaluation method and do some simple introduction, using fuzzy comprehensive evaluation method is mainly because the general evaluation method are focused on qualitative evaluation, subjectivity is too strong, the lack of scientific, and fuzzy analysis method will change the qualitative appraisal to quantitative evaluation, effectively avoid the problem. The concrete evaluation index is shown in figure 3.

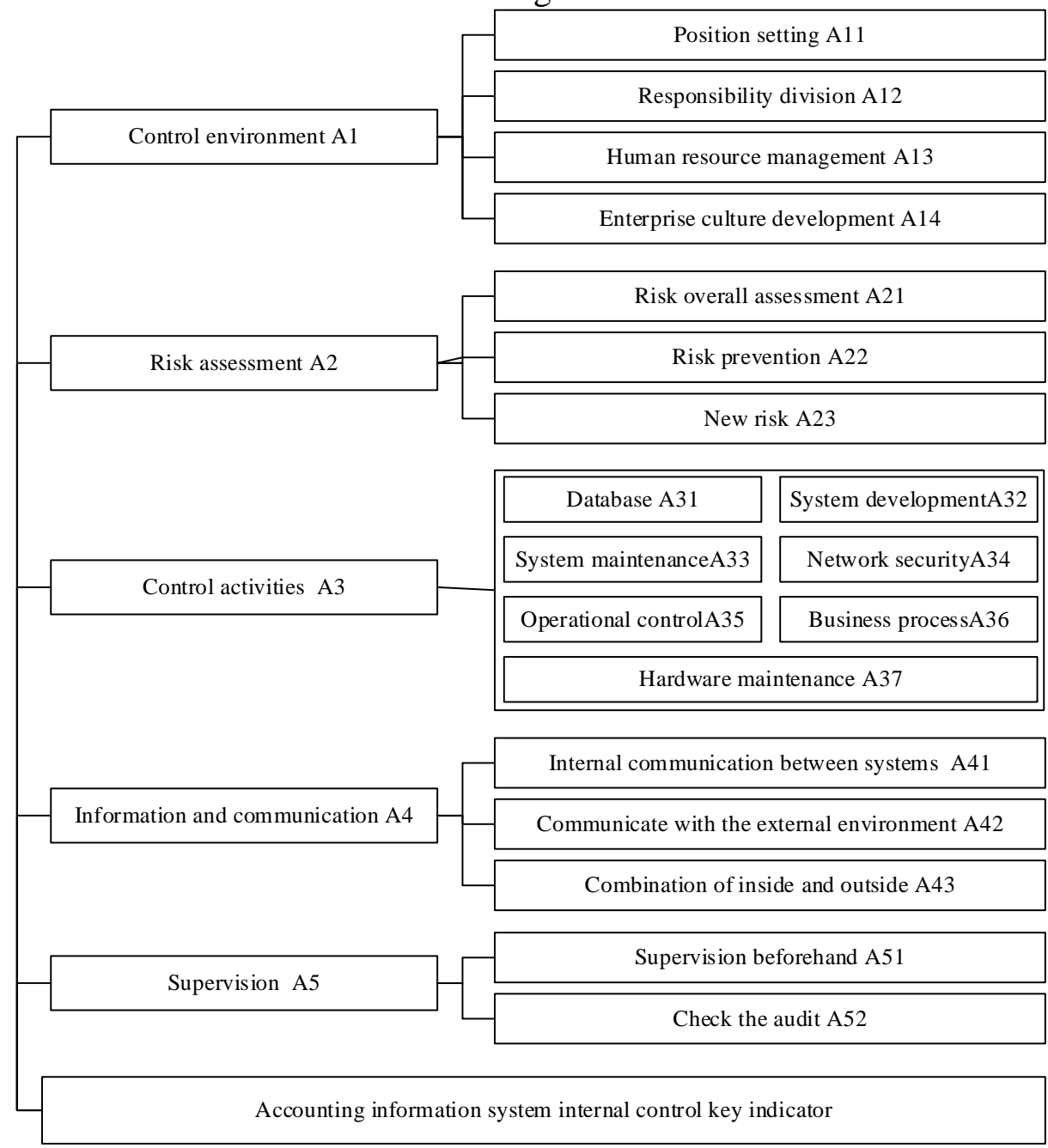

Figure 3. Evaluation indicators of accounting information system internal control based on OPM3 model

By evaluation of enterprise to communicate with the related departments before evaluation work, enables the evaluation to gain support and cooperate with relevant departments, ensure the evaluation work to develop smoothly. When the evaluation scheme, it will evaluation plan issued to each department, at the same time, each department should arrange evaluation staff supervision, the 
results of the survey, by department head sign the papers of the evaluation work, to ensure the reliable of the evaluation work. Sorting summary will collect good evaluation data, and verify the authenticity of the collected data, according to OPM3 model, comparing the information needed to sort out the needed information, analysis and evaluation, the final evaluation report by the conclusion, namely enterprise's stage of evaluation grades.

\section{Conclusion}

This article through to the internal control of accounting information system under the network environment, the accounting information system of internal control to quantify, combining with the organizational project management maturity model of accounting information system internal control OPM3 model is put forward, make the accounting information system of internal control can also be quantitatively evaluation. On the five elements of internal control is explained after respectively, selected the each factor to the implementation of quantitative index and control points, and then to analysis of each control point. Accounting information system internal control with organizational project management maturity model (OPM3 model) to research and analysis, makes the study of the internal control method from qualitative research to quantitative research, the evaluation results can directly show more, at the same time also convenient information demanders understanding of enterprise accounting information system internal control.

\section{References}

[1] P. Trkman, K. McCormack, and M.P.V. De Oliveira: Decision Support Systems, Vol.49 (2010) No.3, p. 318.

[2] K. Schwalbe. Information technology project management [M]. Cengage Learning, 2013.

[3] A. Simon, P. Schoeman, and A.S. Sohal: Journal of Enterprise Information Management, Vol.23 (2010) No.1, p. 100.

[4] H. Lak, M.S. Parvar, M.A. Khosravi: Asian Journal of Research in Social Sciences and Humanities, Vol.4 (2014) No.2, p. 392.

[5] A. Hemmati, M. Hemmati, and M. Ahmadifard: Middle-East Journal of Scientific Research, Vol.12 (2012) No.10, p. 1391.

[6] G. Jia, Y. Chen, X. Xue: International Journal of Project Management, Vol.29 (2011) No.7, p. 834. 